\title{
Introduction
}

\author{
Lowell Dittmer
}

China's contentious relation to Taiwan began when the People's Republic of China (PRC) was founded in October 1949 and the defeated Kuomintang (KMT) set up an exile regime on the island two months later. Without now delving into the rich legal and historical complexities, suffice it to say that the island's autonomous sovereignty has been in contention ever since, initially because of the KMT's stubborn insistence that it continued to represent not just Taiwan but all of China, and later, when the tables had turned, because Taiwan refused to cede sovereignty to the now dominant power that had arisen on the other side of the Strait. At this writing, the election of a Democratic Progressive Party (DPP) government under Tsai Ing-wen in January 2016 brings the island to a new inflection point. For, like the Chen Shui-bian administration in 2000-2008, the incoming DPP regime would really prefer to drop all claim to be part of the Chinese mainland and to embrace political independence. Of course they dare not say this in so many words because it would infuriate Beijing, which continues to insist that there is one China, that Taiwan is a part of it, and that any assertion otherwise by Taiwan constitutes an illegal attempt at secession that Beijing has the legal right to prevent by force. China would prefer that contingency not to arise. Its use of force against Taiwan would result in great damage to the lives and property of people with whom mainlanders share a Chinese ancestry (compatriots in an ethnic or cultural sense, tongbao) whom the PRC aims to return to the motherland's embrace and possibly to the mainland as well. Chinese military forces still respect the striking power of Taiwan's armed forces and wish to avoid the possibility of US intervention to defend the island's sovereignty (even though the United States no longer formally recognizes that sovereignty). Such escalation could well cause great harm to China, to 
Taiwan, and indeed to the United States. In other words, the Taiwan Strait remains an international flash point, one of the few places in the world that could unleash war between two great powers, both of which are nuclear weapon states.

But one of the things that makes Taiwan so politically difficult and so intellectually fascinating is that it poses not merely a security problem but a nexus of interrelated puzzles. The following chapters focus in turn on three of its aspects. The first is "national identity." This is a problem that Taiwan should not be permitted to have, according to mainland critics, because it is not even a nation. Yet Taiwanese do share a sense of collective identity that is widely perceived there as distinct, which they seek to preserve and profess to be willing to fight for. This has greatly complicated Beijing's quest to promote reunification, particularly after the post-1979 shift from a focus on "armed liberation" to a focus on peaceful reunion, for to be peaceful it must also be voluntary. The second aspect of the problem is socioeconomic. The post-1979 shift to peaceful reunification was premised on the assumption that through "three direct links"-postal, transportation, and trade-the embittered gulf dividing the two peoples at the Strait could eventually be bridged. While the "three links" met with an immediate "three nos" (no contact, no compromise, no negotiation) from the Chiang Ching-kuo regime, Beijing nevertheless persevered by accommodating "three indirect links" (mainly via Hong Kong), and these informal connections, unsuccessfully repressed but ultimately tolerated by the Taiwan authorities, have proved surprisingly robust, paving the way for their formalization in 2008. Yet communication has not exactly blossomed into fraternal love. The third dimension of the problem is political-strategic. This has both national and international aspects. Nationally, what do China and Taiwan expect of their future relationship - what adjustments will each demand of the other in terms of structural political changes, or what nonchanges will each tolerate-and how do they plan to effect such changes? Internationally, how will reunification be achieved-or, how can Taiwan's autonomy be preserved-in the prevailing balance of power, and what impact will either outcome have on that balance?

\section{NATIONAL IDENTITY}

A sense of national identity has long been conceived by political scientists to be a vital part of nation building, as it instills loyalty and participatory zeal in an ethnoreligiously heterogeneous citizenry and a sense of collective coherence and international affiliation or direction in the nation-state. At the same time, in extreme cases it can drive blind and ultimately self-destructive international ambitions. The Chinese sense of identity with regard to Taiwan and other peripheral regions has been fairly stable, even spanning both Nationalist and communist revolutionary eras: the understanding is that all of these areas should be assimilated into the motherland as soon and as fully as possible, making minimal 
allowance for ethnolinguistic differences. ${ }^{1}$ In contrast, the sense of national identity in Taiwan has varied greatly over time, recurrently tending to destabilize the relationship. Taiwan attained provincial status in the Qing Empire only ten years before being forfeited to Japan as part of the Shimonoseki peace settlement at the end of the first Sino-Japanese War in 1895, thenceforth remaining a Japanese colony for the next fifty years. Upon occupying the island after 1945, the Nationalist forces reintroduced a Chinese identity for it, initially as a backward outpost of the lost republic but after loss of the civil war as temporary capital of a government in exile. While there had been resistance to the Japanese occupation regime, it seems to have been less than in the contemporaneous Korean colony, and postcolonial Taiwan has also remained friendlier to Japan than either South or North Korea, affiliating Taiwan during the Cold War into a US-Japan-Taiwan security network. All these identity adjustments were superimposed from the top down on a relatively passive populace.

With the introduction of democracy in the twilight years of the Chiangs' reign at the end of the 1980s, the evolution of national identity on the island was stimulated by diverse impulses, including a scrambled international scene at the end of the Cold War, an attractive offer for peaceful reunification from the mainland, and the aspirations of the newly enfranchised Taiwanese electorate. As Yi-huah Jiang, former premier of the Republic of China and professor of political science at Taiwan University, indicates in chapter 2 of this volume, the overall thrust of Taiwan's evolving identity tended to be "modernist." Drawing on the pattern-variable distinction between ascribed and achieved identities, he shows how the primordial division, a "subethnic" split between original inhabitants of the island (benshengren) and the wave of Chinese who fled the mainland at the end of the civil war (waishengren), has gradually faded over time. This is evinced not only in the growing number of citizens who answer the survey question "I am" with "Taiwanese" (as opposed to "Chinese" or "both") but in more refined survey instruments of his own devising that measure identity in terms of various constructed variables. And this corresponds with a "future nation preference" shifting ever more toward independence and away from any interest in reunification. All this is quite contrary to the preferences of the mainland, of course, which is thereby incentivized to reconsider its option to resort to force if Taiwan moves toward formal independence. Yet ironically Jiang finds that while majority preferences have shifted toward independence they are not strongly held: only a small percentage would still pursue independence in the face of a credible threat of force. The Taiwanese electorate is pragmatic, willing to subordinate ideal preferences to political survival. Hence the consistent majority preference for "no independence, no reunification" ( $b u d u b u$ tong). In view of the fairly invariant attachment to a cross-Strait status quo, Jiang argues that the more relevant issue is not identity but the interpretation of "one China." If the PRC and ROC agree that, despite the existence of two governments 
that claim to be "China," there is only one China in the world, who is its legitimate representative, and what repercussions do differing interpretations of "one China" have for policy and diplomacy? In other words, the essential question is one of sovereignty: Who rules?

In chapter 3, one of the few extant studies of the evolution of national identity in Taiwan during the Ma Ying-jeou era, Jean-Pierre Cabestan arrives at the rather startling finding that despite a landslide victory for this Nationalist president in 2008, followed by rapid and successful moves toward reconciliation with the mainland, the Taiwan electorate's interest in reunification has only waned. And this, he argues, is not because the "Blue" camp (a coalition of parties, most predominantly the KMT and the People First Party, that takes a softer position toward the PRC, supporting a reunification that is often envisioned as long-deferred and as dependent on the PRC's fulfillment of many conditions, as well as an increase in ties with the mainland) simply avoided an unpopular issue. To the contrary, the Nationalists made a concerted drive during their eight-year control of both executive and legislative branches to reverse the DPP's foregoing "de-Sinification" movement and restore faith in "one China," interpreted as the Republic of China (ROC) on Taiwan. Cross-Strait trade and investment increased, regular discussions were resumed between the Taiwan's Straits Exchange Foundation (SEF) and China's Association for Relations Across the Taiwan Straits (ARATS), resulting in some two dozen agreements, most prominently the "three direct links" and the 2010 Economic Cooperation Framework Agreement (ECFA), and mainland tourism and investment in the island was for the first time permitted. Having already passed a law against "secession," Beijing downplayed its invasion threats and agreed and adhered to a diplomatic truce, permitting Taiwan to make trade agreements with New Zealand and Singapore that it could have blocked and to participate informally in the World Health Association. The mainland authorities even agreed to negotiate cultural exchanges and some form of peace treaty with the island. But after initially expressing interest the Ma leadership opted not to pursue these. And the attempt to move ahead toward further economic integration in a Cross-Strait Service Trade Agreement (CSTA), after being bilaterally agreed on, was blocked in the Legislative Yuan, where the KMT held a commanding majority.

The PRC authorities must have been quite perplexed that a relationship they had so carefully nurtured and that seemed to be making excellent economic progress could so swiftly unravel. How could this be? Cabestan points to a number of unnoticed flaws with cross-Strait détente. First and foremost, increasing economic linkages with the mainland did not prove to be quite the panacea that had been advertised. Exports constitute about 70 percent of Taiwan's GDP, some 40 percent of which go to China or Hong Kong. But PRC growth has been decelerating since 2010 for a number of reasons, none of which have much to do with Taiwan, nor have the island's other trade partners made a very impressive recovery from the 
global financial crisis, so export growth stalled. There is a perception (only weakly supported by available evidence) that the growth that has occurred has been more unequally distributed (to businesses with mainland investments) than before. The economic "gifts" bestowed by the PRC, such as "early harvest" post-ECFA trade arrangements, tend to be discounted in Taiwan for having ulterior political motives (which China has never denied). The student-led, anti-CSTA "Sunflower Movement" that occupied the legislature several weeks in the spring of 2014 seems to have been surprisingly successful in mobilizing mass support, especially among the young people ironically most likely to seek jobs on the mainland. It seems that the more economic integration succeeds, the greater the tendency to mobilize national identity as a counterweight.

Chapter 4, by Shu Keng and Emmy Ruihua Lin of the Shanghai University of Finance and Economics, takes on one of the key pieces of this puzzle, namely the political opinions of the growing number (currently estimated at over a million) of Taiwanese businesspeople or taishang who move to the mainland on a more or less permanent basis to pursue their livelihoods. On the basis of an extensive (452 respondents) survey of Taiwan sojourners in Dongguan and the Shanghai region, Keng and Lin indeed find many changes: these Taiwanese are happy to assimilate to mainland culture, to marry Chinese spouses and have children, and to set up their own business associations, even schools. Their attitudes toward the mainland do change as well: they are more likely to vote "Blue," less likely to endorse Taiwan independence (the percentage sinks drastically, from 25.8 percent to 3.5 percent), and more likely to be open to future reunification (the percentage more than doubles, from 9.9 percent to 21.4 percent). The puzzle is that despite all these adaptations they are not inclined to give up their Taiwanese identity. They even continue to prefer independence to reunification, by a wide (if reduced) margin. Why? Keng and Lin attribute the resilience of Taiwan identities to taishang mobility: because they can quickly and easily return, they continue to view Taiwan as "home." There may be other answers as well to this underresearched and methodologically elusive question. Class may be a factor-living standards remain much higher in Taiwan than on the mainland (even though sojourners typically still draw Taiwanese salaries). And sojourners tend to limit their assimilation, forming their own clubs, social networks, schools, and communities on the mainland. Finally, politics-though ideology is played down, and Taiwan's democracy is often derided in China as chaotic and corrupt-may play a role. It may take generations (e.g., children of Taiwan-Chinese marriages) for full identity convergence to occur.

The Chinese insist that the mainland population should also have a voice in the future of Taiwan, and although this is often disputed on the island, in view of the PRC's looming economic and military power it seems inevitable that it will. In chapter 5, Gang Lin of Shanghai Jiaotong University and Weixu Wu of Tsinghua University bring a perceptive Chinese perspective to the issue. Understandably, 
while Taiwanese intellectuals tend to focus on national identity as "constructed," the mainland preference is to view it as primordial-as Chinese president Xi Jinping put it in his 2015 Singapore meeting with Ma Ying-jeou, "No force can pull us apart because we are brothers who are still connected by our flesh even if our bones are broken, we are a family in which blood is thicker than water." Mainlanders invoke a shared culture, again viewed not as malleable but as primordial: the path-dependent culture laid down by Confucianism, which the People's Republic now honors along with Taiwan. The future is also evoked as a sentimental basis for togetherness: the two peoples constitute a "community of cross-Strait shared destinies." The complex issue of institutional integration (i.e., mutual structural adjustments) is postponed with the "one country, two systems" formula that assures Taiwan even more latitude than Hong Kong's Special Administrative Region for the next fifty years. Successful integration of taishang into mainland society supposedly illustrates the potential for integration without institutional convergence. At the same time Chinese tacitly concede the weakness of their approach, noting that civil identity has fallen behind ethnic identity as a force for reunification. The possibility that the People's Democracy might at some future point usefully emulate Taiwan-style structural reforms is rarely entertained (and never officially).

Mainland views of the Taiwan issue are difficult to research because public opinion polling on that sensitive topic is not permitted, no doubt because Beijing's hopes for peaceful reunification could well be derailed by an outburst of Chinese nationalism. In chapter 6, Rou-lan Chen thus tackles the even more volatile but still uncensored issue of the Senkaku Islands, known in Taiwan (to which they are closest, some 43.5 miles away) as Diaoyu Tai and on the mainland as Diaoyu Dao. Japan surveyed the eight tiny uninhabited islets, declared them terra nullius, and annexed them under the jurisdiction of Okinawa prefecture in 1895; ever since their occupation by the United States from 1945 to 1971 they have been under Japanese control. Since the discovery of potential subsurface hydrocarbon deposits in the area in 1968, Japanese sovereignty has been disputed by both Taiwan and the PRC. Beijing's claim to the islets is subsidiary to its claim to Taiwan, as it contends (despite Tokyo's claims to the contrary) that they were part of the "unequal" Shimonoseki treaty ceding Taiwan to Japan. Although the islets are also claimed by Taiwan (much to China's satisfaction), their parallel provenance and proximity make them a politically accessible synecdoche for China's claim to Taiwan, and as such a polemical target of China's nationalistic "raging youth" (fen qing). Chen analyzes this politically articulate subsection of Chinese civil society through a sample of over a thousand contributions to a quasi-official Internet bulletin board called the Strong Nation Forum. In a fascinating psycho-political analysis of these data, she finds that the outraged nationalism provoked by the issue symptomizes deep ambivalence in China's younger generation. Their rage is directed partly against Japan, for claiming property that rightfully belongs to China, but 
also against the Chinese Communist Party (CCP) leadership for responding with such weakness and timidity to this violation of national sovereignty. This sense of nationalist outrage, which has upon occasion taken the form of mass demonstrations and even collective vandalism, may be traced to the massive expansion of the education system since 1999, the decay of established institutions of collective identity (e.g., the Communist Youth League), rising expectations after several decades of double-digit growth, and limited job opportunities for young people. Whatever the socioeconomic reagents, it seems to be a recurrent pattern of explosive youthful activism.

\section{POLITICAL ECONOMY}

In chapter 7, Chih-shian Liou begins our discussion of political economic connections with a comparative analysis of state-owned enterprise (SOE) in China and Taiwan. As an isomorphic component of Leninist "commanding heights" state-led developmentalism on both sides of the Strait, the SOE provides a useful point of departure. Though SOEs in China and Taiwan have the same origin, they have since undergone diverging trajectories. In the PRC they have been ideologically identified with socialism and thus favored with subsidies, preferred bank loan terms, merger and acquisition opportunities, initial public offerings, and stock market listings, and, in a number of "pillar" or strategic industries, they have been protected from market competition. Though subject to a series of reforms since the 1990s, SOEs continue to enjoy de facto soft budget constraints, while the directors are appointed by the Organization Department of the CCP Central Committee and have ministerial rank. The state has tried to make SOEs "national champions" able to compete with multinational corporations globally, thanks to which the second- and third-largest corporations in the world (Sinopec and China National Petroleum Corporation, respectively) are both SOEs. Though SOEs in 1978 made up three-quarters of China's GDP and have shriveled to only about one-quarter of that today, they are likely to remain in a privileged upstream industrial position under CCP control. In Taiwan, on the other hand, while SOEs played a key role in the early industrialization stage, privatization policy was introduced in the late 1980s. Thus, while SOEs accounted for 35.2 percent of capital formation in 1961, by 2001 they accounted for only about 9 percent. In contradistinction to Japan, South Korea, and China, Taiwan's growth has been led by small and medium enterprises (SMEs), usually family controlled. The pioneering dimension of Liou's analysis relates this comparative analysis to the dynamics of cross-Strait economic relations. Depending on the ideological emphasis at the time, SOEs are politically preferred to foreign-invested enterprises (FIEs), and this will tend to crowd out Taiwan-invested capital on the mainland. Growing cross-Strait economic interdependence, Liou points out, 
also raises the issue of trade externality: "In general trade among allies generates a positive security externality while trade among nonallies generates a negative security externality." Finally, there is the issue of economic asymmetry: the proportion of Chinese trade with Taiwan is much smaller than the proportion of Taiwan's trade with China (over 30 percent), meaning Taiwan is more dependent on China than vice versa. To deepen bilateral economic integration the mainland has consistently permitted an imbalance of payments very much in Taiwan's favor, also making the China-Taiwan trade relations more valuable to Taiwan than to the PRC.

Chapter 8, by Chung-min Tsai of National Cheng Chi University, focuses squarely on cross-Strait trade and investment and its impact on politics. Trade and investment, he finds, have increased inexorably over time, giving rise to Chinese confidence that economic integration must eventually lead, in accordance with neofunctional (and Marxist) logic, to political integration. In Taiwan's case, trade was soon followed by investment, and as investment increased it pulled in related trade. There were four big waves of Taiwan investment in China: (1) in the late 1980s, after the appreciation of Taiwan's currency priced Taiwan out of American markets and the government removed constraints on capital outflow; (2) 1992-94, after Deng's "southern voyage" inaugurating a new wave of liberal economic reform and coinciding with the Singapore talks; (3) in the early 200os, during the world high-tech recession, when Taiwan's computer industry moved to the mainland to remain price competitive; and (4) post-2010, following the signing of the ECFA with its "early harvest" enticements. As the connection thrived, Taiwan capital has moved from labor-intensive assembly to high-tech production, from south to north and from east to west, from a more general export orientation to a focus on the China market. What is perhaps surprising is that the nexus between economics and politics has certainly not gone unnoticed in Taiwan, and politicians opposed to unification, such as Lee Teng-hui and Chen Shui-bian, have taken steps to arrest its development.

And what has been the impact of politics on economic integration? Attempts under Lee Teng-hui's presidency to "go slow" (jieji yongren) on investment in the mainland and divert it to Southeast Asia may have had some temporary impact in the wake of the 1995-96 missile crisis. But the Asian financial crisis (1997-98) then scared taishang out of Southeast Asia, and in the early 2000 s the mainland eased foreign direct investment (FDI) regulations. For their part, Chinese attempts to co-opt taishang seem to have had some effect on voting patterns (most vote "Blue"), but not on policy making in Taiwan. Though the evidence is not entirely clear, Tsai concludes that the impact of political pressure (by either side) on trade and investment has been negligible. Economic transactions actually increased following the 2000 election of DPP leader Chen Shui-bian (because of the high-tech crash) and decreased following the 2008 election of KMT leader Ma Ying-jeou 
(because of the global financial crisis) - in each case, economic considerations trumped political.

Still, the prospects for the economic relationship going forward are decidedly mixed: election of a DPP leadership will not incentivize PRC political cooperation, mainland wages have been escalating, Beijing has been trying to upgrade its own national champions at the expense of competing foreign enterprises, and of course there has been an overall slowdown of GDP growth. Taiwan faces the contradictory pull of mainland jobs and opportunities departing the island while leaving an antimainland political backlash behind. In 2015 the United States was Taiwan's largest export destination by country, as trade with China slumped because their expanding domestic supply chain decreased demand for Taiwanese components. ${ }^{2}$ Meanwhile, encouraged by the PRC leadership to "go out" (zuo chuqu) and acquire brands and expertise abroad, mainland enterprises have invested some $\$ 1.3$ billion in the Taiwan market, where they received a mixed popular reception. Recent attempts by the state-owned chip maker and IT giant Tsinghua Unigroup to shell out \$2 billion for substantial stakes in two Taiwan chip-packaging companies, Silicon Precision Industries Co. (SPIL) and ChipMOS Technologies Inc., have raised eyebrows in business and political circles on the island, for example.

In chapter 9, Tse-Kang Leng of the Academia Sinica in Taiwan focuses specifically on information technology (IT), the Silicon Island's leading strategic sector since the 1990s, constituting 30 percent of its exports. According to the original conception of the cross-Strait division of labor in Taiwan's industrial policy, the technology-intensive crown jewels were to be kept at home while labor-intensive assembly work was downloaded to the mainland. But that plan went overboard in the high-tech crash of the early 20oos, when Taiwan's laptop industry relocated to keep prices competitive-if one left, the rest had to follow or see their prices undercut by the one that left. Despite its ever growing importance, the cross-Strait nexus is only part of Taiwan's globalization. Taiwan is part of a tangle of valueadded chains in which the upstream is largely in the United States and Japan while the downstream (assembly and export) is located on the mainland. Taiwan has found its niche in the middle, in ODM (original design manufacture) and OEM (original equipment manufacture) production. This niche is, however, endangered by competition from Japanese and Korean firms like Samsung upstream, while the Chinese plan is to move up from downstream by co-opting or buying or otherwise displacing Taiwanese OEM producers and semiconductor fabrication plants and forming a "red supply chain." To avoid being squeezed out, Taiwan firms have been attempting to move upstream from OEM to OBM (original brand manufacture), that is, to control the entire chain including the brand, as in Acer laptops or HTM smart phones. But this is a challenge amid stiff international competition, and it remains to be seen whether Taiwan firms can master the logistic and network requirements. Taiwan must simultaneously "handle the two situations" of 
international commercial competition and domestic security (in which industrial leadership and technological innovation have also become securitized).

In chapter 10, by You-tien Hsing, professor of geography and chair of the Center for China Studies at the University of California at Berkeley, we shift focus from the economic to the social dimension of cross-Strait relations. Hsing focuses on the proliferation and political organization of social media, which has emerged as a functional complement and sometime nemesis to industrial expansion on the island. Taiwanese businesspeople have sometimes tended to charge ahead oblivious of negative externalities such as high-tech or petrochemical pollution (in which they are hardly unique), creating fertile ground for social entrepreneurs and informal media networks such as PeoPo to harness "not in my back yard" (NIMBY) sentiments. And these have sometimes had major impact. Indeed, this has been one of the factors facilitating the wholesale exodus of externality-freighted production facilities such as Foxconn to the mainland, where environmental activism is less problematic. In this sense, Taiwan's democratic social entrepreneurialism might be said to make an ironic contribution to cross-Strait economic integration. China for its part, with the largest number of netizens and social media users on the planet, has also experienced electronically enhanced political involvement. Netizens have been active in fighting unfair land expropriations, pollution, corruption, health care abuses, and foreign investors. They have, for example, engaged in spontaneously assembled "human flesh searches" that use the Internet to identify and harass demonstrably corrupt officials, and in some cases (e.g., the 1986 anti-Japan demonstrations) have used social media to organize public protest. The widespread political use of social media has been particularly impressive in view of the state's various efforts to steer or suppress it, making the public context quite different from Taiwan's in that standing networks such as PeoPo cannot be established without state links. But Taiwan also has developed more politically acceptable contributions to cross-Strait civil society. The Tzu Chi organization, a Buddhist charity and one of the largest philanthropic organizations in the world, is based in Taiwan but is also fully functional on the mainland, where it propagates quasi-socialist values, does not endorse electoral democracy or market capitalism, and constitutes no threat to the state in either Taiwan or the PRC.

\section{POLITICAL STRATEGY}

Taiwan is in an unusual position in that its number one threat to national security is also its leading trade partner and investment recipient. In chapter 11, Yu-Shan Wu of Taiwan National University and Academia Sinica places Taiwan's unusual but not unique position in a strategic theoretical framework for comparative analysis, focusing on the recent security dilemma of Ukraine. Ukraine also has close historical, cultural and economic ties with a much larger neighbor, the Russian 
Federation, which under Putin has moved to strengthen those ties. Ukraine attempted to resist Russian encroachments by balancing them against the European Union's expansionist ambitions. Ukrainian resistance was however complicated by a precarious domestic balance of power between one leadership faction (i.e., Yulia Tymoshenko) tilting toward affiliation with the EU and another (i.e., Viktor Yanukovich) tilting toward Russia’s rival Eurasian Union. When this delicate balance collapsed in the Euromaidan demonstrations (and their suppression) and the flight of Yanukovich, Russia employed thinly disguised military force to reassert its predemocratic hegemony. Taiwan's strategic position is in many relevant respects analogous. True, Taiwan has had a much longer period of effective independence from China (over a century), and, like England, it is a maritime state facing a continental power across a defensible body of water (the Taiwan Strait). But like Ukraine, Taiwan has close historical, cultural, and economic ties to a much more powerful neighbor, which has asserted even more explicitly than Russia its claim to sovereignty over the island and its legal right to take it by force. Like Ukraine, Taiwan seeks to balance China's claims against an American informal and ambiguous pledge of security support without denying its historical, cultural, and economic ties to the mainland-that is, to "hedge." Was Ukraine's failure one of refusing to commit or of trying to commit to both sides at once? Is Ukraine's current embattled situation Taiwan's future? Of course no one knows the future, but the thrust of the Ukraine experience suggests that the position of a relatively weak "pivot" balancing two great powers becomes highly tenuous if relations between the wings polarize, leading each to pressure the pivot to "choose sides."

Chapters 12 and 13 focus on the other two angles of Taiwan's strategic triangle. With regard to American policy, we see an awkward gap between formal diplomatic ties and informal security commitments. In accordance with a "one-China policy" that required states to officially recognize only the ROC or the PRC, Washington recognizes the PRC as the one and only China; it dropped both its former defense alliance and its diplomatic recognition of Taiwan in January 1979. The United States and China have built their relationship upon recognition supplemented by three communiqués $(1972,1979$, and 1982), reinforced by a booming bilateral trade and investment relationship, and the relationship has resulted in important strategic agreements on specific issues such as nuclear proliferation and climate control. Yet the United States has hedged by inserting into its recognition documents a provision for continued sale of weaponry to a Taiwan it no longer formally recognizes and by a law (the Taiwan Relations Act) implying continuing (if ambiguous) security protection and upgrading the informal relationship. In chapter 12, Ping-Kuei Chen, Scott L. Kastner, and William L. Reed debate the proposition put forth by some critics of American China policy that this is not only ambiguous but inconsistent and surely detrimental to closer Sino-American cooperation, that the United States should hence rescind its informal security 
commitment to Taiwan, and that, since it has already withdrawn from its defense alliance and diplomatic relationship with Taiwan it should withdraw as well the last symbol of support, weapons sales. In this exercise in rational futurology that conceives of "independence" and "reunification" as the authors do, it may indeed be correct that if the United States stopped selling weapons morale in Taiwan could collapse and the leaders would become more willing to reunite with the mainland on Beijing's terms - a result that would damage the US regional strategic position and its reputation for honoring security commitments. But Chen, Kastner, and Reed argue that inasmuch as this is only one possible scenario and not necessarily the most likely one, it would be risky for the United States to rescind weapon sales and for China to apply sanctions to force it to do so. Why? First, cessation of weapons sales would not necessarily make Taiwan more willing to submit to the mainland or make the United States more willing to allow the island to be overrun by force-after all, the United States had no formal security commitment to Korea when it intervened to resist a North Korean attack in the summer of 1950 (an alliance was agreed in 1953), or to South Vietnam in 1964. For the United States to halt weapon sales would make Taiwan a weaker and a more vulnerable target for PRC coercion, but it would also make Taiwan a more sympathetic victim for the Americans to rescue in the face of an unprovoked attack, as the futility of selfdefense against an overwhelmingly superior adversary would be immediately apparent. Taiwan's reactions are not necessarily based on rational calculation of the power balance, and American reactions are not entirely predictable on the basis of paper commitments.

Whereas American defense of the cross-Strait status quo is aimed at avoiding destabilizing uncertainties, China is betting on statistical probabilities: it is growing faster and stronger and is confident that time is on its side. Yet China is also wary of destabilizing collateral damage (let alone war with the United States) and would very much prefer peaceful reunification. According to Jing Huang of the Lee Kuan Yew Institute at the National University of Singapore, the Chinese have relied upon both carrots (socioeconomic integration) and sticks (the ultimate threat of overwhelming force). But since carrots have thus far proved inconclusive and the use of threats of force has had negative side effects in terms of mobilizing an antimainland backlash in Taiwan and degrading Chinese soft power abroad, Beijing has shifted from demanding reunification within a defined time span to proscribing movement toward independence. Under $\mathrm{Hu}$ Jintao and Xi Jinping, Beijing's prime emphasis has not been sticks or new carrots but a gradual constriction of diplomatic and political space: "boxing Taiwan in," as Huang puts it, so that Taiwan eventually realizes that it has no rational way out but through Beijing. This gradual attrition strategy must be delicately nuanced, giving Taiwan enough space to avoid a negative backlash and encourage pro-China sentiment but not enough to set back the isolation strategy or give the island the illusion it could 
break out from it. Under Xi Jinping this subtle balance has tended to shift, like Chinese foreign policy generally, to a slightly more assertive stance, for example in his reaffirmation of "one country, two systems," or his emphasis on "one China" over "differing interpretations." This harder line may become still harder during the forthcoming Tsai Ing-wen era. Yet overall the strategy might be said to have been at least a quasi-success in that it has won the limited approval of the "Blue" camp and the industrial interests with a stake in the mainland economy, the tolerance of the United States, and an overwhelming diplomatic united front in international diplomacy. But as the Sunflower Movement and the results of the January 2016 election illustrate, just because Taiwan is trapped does not necessarily mean they love their trapper.

Taiwan in the 1990s looked to Southeast Asia as a possible way out, as chapter 14, by Samuel Ku of National Kaohsiung University, notes in his interesting account, partly because the revaluation of the currency (under American pressure) squeezed exports and partly because it wanted to lessen its excessive economic dependency on the mainland. Although the island lost its last battles for diplomatic recognition against the PRC in Indonesia and Singapore in 1990 and Brunei in 1991, Lee Teng-hui's "vacation diplomacy" helped maintain informal friends and business contacts there, and Taiwan has established Taiwan affairs offices in all Southeast Asian countries to facilitate trade, investment, and travel. As of 2010, the Association of Southeast Asian Nations (ASEAN) was Taiwan's second-largest trade partner after the PRC, with US\$93.64 billion in trade by 2014 (15.9 percent of Taiwan's total trade). While China's involvement in the Indochina wars and number of other Southeast Asian "national liberation struggles" alienated Southeast Asian governments during the Maoist period, China announced a "good neighbor policy" in 1990, and in the early 1990s it signed the Treaty of Amity and Cooperation (TAC) and joined the ASEAN Regional Forum (ARF), then attended ASEAN Plus Three meetings promoting north-south collaboration and the East Asian Summit. The real breakthrough for China came during the Asian financial crisis (1997-98), when it made generous loans to Thailand and Indonesia while the International Monetary Fund (IMF) imposed strict austerity conditions on its bailout packages. In 2001 the Boao Asia Forum was established to facilitate informal pan-Asian "track two" diplomacy, and in 2010 the China-ASEAN Free Trade Agreement (CAFTA) came into effect, the largest such free trade agreement in the world, quickly catapulting China to the leading position among most ASEAN trade partners. With its launch of the Asian Infrastructure Investment Bank in 2014 and its proposal, in 2013, of the boldly visionary "One Silk Road Economic Belt and one Twenty-First-Century Maritime Silk Road," an initiative to establish economic corridors connecting China with other countries in Central Asia, West Asia, Southeast Asia, and Europe, China appears to be moving not only to further expand its influence in the region but to claim entrepreneurial leadership. Yet at 
the same time China's maritime territorial claims over the South China Sea and its increasingly forcible efforts to enforce them have not been welcomed by any Southeast Asian nation. In the face of China's economic and diplomatic initiatives, Taiwan under Ma Ying-jeou abandoned Chen Shui-bian's vigorous but ultimately failing "scorched-earth" competition with the mainland in favor of a nonconfrontational survival strategy that tacked somewhat closer to PRC positions. While Taiwan might have expected to benefit from the backlash against China's overbearing regional presence, Taiwan's position is compromised by the fact that its maritime territorial claims are identical to those of the PRC (indeed, based on the same "eleven-dash-line" 1947 map). Taiwan under Ma adopted an ambiguous policy, attempting to differentiate its gentler enforcement policy from the mainland's without relinquishing its sovereignty claims. At the same time the taishang, as ethnic Chinese alongside an economically influential ethnic minority in Southeast Asia, seek to ride the coattails of the mainland in private business ventures as well as the Asian Infrastructure Investment Bank and the Maritime Silk Road.

\section{CONCLUSION}

Taiwan, just when it seemed to have put the endlessly nettlesome cross-Strait problem to rest after a decade of cordial and constructive relations, appears to have resurrected it with the landslide defeat of its political sponsors. President Tsai Ing-wen has made clear her preference for no trouble with the mainland, and perhaps she will have none. But even on the off chance that this turns out to be true, the election itself says a great deal. While the results still need to be sorted out thematically in terms of the distribution of voter dissatisfaction with the $\mathrm{Ma}$ regime (clearly leadership failure must play a large part: e.g., Wang Jin-pyng), a portion of that discontent must be attributed to cross-Strait policy, if only because that took such a central place in the Ma agenda. Tsai's presidency must logically be seen to mark a deliberate departure from Ma's cross-Strait policy: otherwise she would not have so steadfastly refused to sign on to the status quo of the "1992 Consensus" - one China Constitution; one China, differing interpretations; no immediate reunification, no independence, and no use of force. Thus we stand at the threshold of a brave new era.

If Tsai maintains her current position of refusing to endorse the 1992 Consensus but "promoting communication, no provocations and no accidents," and holds to her statement that "we will not be provocative, and hope the two sides can sit down and talk in a rational manner," Beijing may not resort to the various economic and diplomatic weapons in its armory, which it cannot easily impose without damage to its own interests. ${ }^{3}$ That would allow the relationship to glide down to a more stagnant phase in which high-level cross-Strait communications are faute de mieux limited to the CCP-KMT Forum. But the relationship even in the best case is apt to be fragile and suspicious. 


\section{NOTES}

1. See Bill Chou, "New Bottle, Old Wine: China's Governance of Hong Kong in View of Its Policies in the Restive Borderlands," Journal of Current Chinese Affairs 44, no. 4 (2015): 177-209.

2. Enru Lin, "Export Orders Down by 4.4 Percent in '15, Economics Ministry," China Post (Taipei), January 21, 2016, www.chinapost.com.tw/taiwan/business/2016/o1/21/456639/Export-orders.htm.

3. Hong Kong Economic Times, December 28, 2015, and Taiwan.cn [Beijing], December 25, 2015, quoted in Willy Lam, "After the Election: The Future of Cross-Strait Relations," China Brief 16, no. 1 (January 12, 2016), www.jamestown.org/programs/chinabrief/single/?tx_ttnews\%5Btt_ news\%5D=44971\&tx_ttnews\%5BbackPid\%5D=25\&cHash=1ed4b9f61c57e3c8deod9oae9gbeo109\#. $\mathrm{VqvH}_{3} \mathrm{HqAMi} 8$. 
